\title{
Decreased Activity of Hippocampal Neurons in Alzheimer's Disease Is Not Related to the Presence of Neurofibrillary Tangles
}

\author{
A. Salehi, M.D., R. Ravid, Ph.D., N. K. Gonatas, M.D., And D. F. Swaab, M.D., Ph.D.
}

\begin{abstract}
Numerous studies have established the key role of the Golgi apparatus (GA) in post-translational processing, transport and targeting of proteins destined for secretion, lysosomes and plasma membranes. Moreover, several studies performed in our laboratories have shown that the size of the immunocytochemically detected neuronal GA is a reliable index of neuronal activity in aging, Alzheimer's disease (AD) and amyotrophic lateral sclerosis. It has been suggested that in $\mathrm{AD}$ there is decreased neuronal activity, e.g. in terms of glucose metabolism and protein synthetic capability. To further explore the hypothesis of decreased neuronal activity in $\mathrm{AD}$, in this study the size of the GA was measured in pyramidal neurons of the CA1 area of the hippocampus of non-demented controls and AD patients. The size of the GA was measured separately in neurons with and without neurofibrillary tangles (NFT). Moreover, in order to establish a correlation between the density of NFT and the size of the GA, the density of extraneuronal NFT was determined around each neuron and related to the size of its GA. The results, quantified by image analysis, indicate that there is a significant reduction in GA size in the neurons of the CA1 area of the hippocampus of AD patients. However, there was no significant relationship between the size of the GA and the presence or absence of intracellular NFT. In addition, there was no correlation between the density of extracellular NFT and GA size of adjacent neurons. These findings are consistent with the conclusion that in AD there is evidence of decreased protein processing and secretion in the affected neurons of the CAl area of the hippocampus. However, we failed to detect a relationship between intracellular or extracellular NFT and neuronal protein synthetic ability. These results justify the hypothesis that in AD a primary lesion is hypoactivity of neurons that is not directly linked with the development of intracellular or extracellular NFT.
\end{abstract}

Key Words: Alzheimer's disease; Golgi apparatus; Hippocampus; Neurofibrillary tangle.

\section{INTRODUCTION}

One of the most prominent neuropathological hallmarks of Alzheimer's disease (AD) is the presence of neurofibrillary tangles (NFT). Microscopically, these cytoplasmic structures are composed of paired helical filaments (PHF), of which the tau protein constitutes the major component. It has been shown that tau, which plays a crucial role in the stability of the neuronal cytoskeleton and axonal transport, is abnormally phosphorylated in AD (1-3). There is a clear relationship between the severity of dementia in $\mathrm{AD}$ patients and the number of NFT (4). However, NFT are not specific for AD, since they can also be found in a variety of other neurodegenerative diseases, such as in Parkinson's dementia of Guam (5) and dementia pugilistica (6). In AD patients NFT are preferentially formed in a rather selective population of neurons, e.g. the pyramidal neurons in the CA1 area of the hippocampus, layers II and IV of the enthorinal cor-

From the Graduate School Neurosciences Amsterdam, Netherlands Institute for Brain Research, Meibergdreef 33, Amsterdam, The Netherlands (AS, RR, DFS); Department of Physiology, Faculty of Medicine, Shahid Beheshti University of Medical Sciences, Tehran, Iran (AS); Department of Pathology and Laboratory of Medicine, Division of Neuropathology, University of Pennsylvania, Philadelphia, PA (NKG).

This work was partly supported by a grant from the Shahid Beheshti University of Medical Sciences, Tehran, Iran (AS) and by the National Institutes of Health (NS05572) (NKG).

Correspondence to: A. Salehi, M.D., Netherlands Institute for Brain Research, Meibergdreef 33, 1105 AZ Amsterdam, The Netherlands. tex, layers III and V of the associative cortex, the locus ceruleus, nucleus raphe dorsalis and septal nucleus.

It has been proposed that decreased neuronal activity and the development of AD changes are associated (7). Protein metabolism is indeed affected in AD. The AD brain contains a lower total amount of protein than that of non-demented controls (8). Furthermore, a clear reduction in total messenger RNA (9), nucleolar volume, cytoplasmic RNA content (10-12) and glucose metabolism (13) has been observed in the cortex of AD patients. In the present study we determined whether changes in secretory protein metabolism as judged by the size of the Golgi apparatus (GA) and cell profile area are correlated with the presence or absence of NFT in the same cell. The GA processes newly synthesized proteins and the size of this organelle can be used as a sensitive index of neuronal protein synthetic ability (14-18).

Since it is presumed that NFT impair neuronal function $(19,20)$, we studied whether there is a relationship between the reduction of protein synthetic ability and the appearance of intra- and extracellular NFT as stained by Bodian. It has been shown that compared with other histochemical methods for NFT staining, Bodian's method visualizes high numbers of NFT in AD brains (21). In earlier studies we showed in AD patients that the pretangle stages of cytoskeletal alterations that are not stained by Bodian but stained prominently by Alz-50 which reacts with a variety of proteins, including phosphorylated tau (22) and other antibodies against cytoskeletal alterations (23), do not affect protein synthetic ability of the area (17). The present study aimed to es- 
TABLE 1

Patient Data

\begin{tabular}{|c|c|c|c|c|c|c|c|}
\hline $\begin{array}{c}\text { Autopsy } \\
\text { no. }\end{array}$ & Sex & $\begin{array}{c}\text { Age } \\
\text { (years) }\end{array}$ & $\begin{array}{l}\text { PMD } \\
\text { (h) }\end{array}$ & $\begin{array}{l}\text { BW } \\
(\mathrm{g})\end{array}$ & $\begin{array}{l}\text { NFT } \\
\mathrm{mm}^{2}\end{array}$ & GDS* & Cause of death/clinical diagnosis \\
\hline \multicolumn{8}{|l|}{ Controls } \\
\hline 1) 88149 & $\mathrm{~m}$ & 58 & 24 & 1,800 & 0.45 & - & Brain infarction, myocardial infarction \\
\hline 2) 90183 & f & 65 & 4.2 & 1,270 & 0.67 & - & Lung carcinoma, massive hemorrhage \\
\hline 3) 90202 & $\mathrm{~m}$ & 72 & 4.2 & 1,330 & 7.60 & - & Myocardial infarction \\
\hline 4) 9190 & f & 80 & 36 & 1,205 & 0.87 & - & Cardiogenic shock \\
\hline 5) 91126 & f & 82 & 48 & 1,100 & 7.89 & - & Myocardial infarction \\
\hline 6) 90203 & $\mathrm{~m}$ & 85 & 4.5 & 1,050 & 1.31 & - & $\begin{array}{l}\text { Myocardial infarction, diabetes mellitus, } \\
\text { lung emphysema }\end{array}$ \\
\hline Mean \pm SEM & & $74 \pm 4.4$ & $20.0 \pm 7.7$ & $1,292.5 \pm 110$ & $3.13 \pm 1.4$ & & \\
\hline \multicolumn{8}{|l|}{ Alzheimer cases } \\
\hline 7) 91092 & $\mathrm{f}$ & 54 & 3.1 & 1,055 & 45 & 6 & $\mathrm{AD}$, cachexia \\
\hline 8) 92140 & $\mathrm{~m}$ & 62 & 6.0 & 1,180 & 21 & 6 & $\mathrm{AD}$ \\
\hline 9) 88252 & $\mathrm{f}$ & 66 & 3 & 1,250 & 85 & 7 & $\mathrm{AD}$, cachexia and sepsis \\
\hline 10) 91118 & $\mathrm{f}$ & 73 & 4 & 1,106 & 28 & 7 & $\mathrm{AD}$, dehydration \\
\hline 11) 90349 & $\mathrm{~m}$ & 77 & 3.5 & 1,168 & 52.7 & 7 & $\mathrm{AD}$, pneumonia \\
\hline 12) 87017 & $\mathrm{f}$ & 83 & 3.3 & 970 & 50 & nd & AD, lung embolism, cachexia \\
\hline 13) 90345 & $\mathrm{~m}$ & 86 & 4.1 & 1,303 & 3.2 & 7 & $\mathrm{AD}$, uremia \\
\hline 14) 91061 & $\mathrm{~m}$ & 88 & 4.4 & 1,058 & 27.3 & 5 & $\mathrm{AD}$, decompensatio cordis \\
\hline Mean \pm SEM & & $73.62 \pm 4$ & $4.0 \pm 3.5$ & $1,136.25 \pm 38$ & $39.1 \pm 8.8$ & & \\
\hline
\end{tabular}

tablish whether there is a relationship between advanced stages of cytoskeletal changes, i.e. NFT, and neuronal protein synthetic activity as judged by the size of the GA. We measured the size of the GA in NFT-bearing neurons in the CA1 area of the human hippocampus. This area is consistently affected in AD by neuropathological changes, i.e. NFT and senile plaques (SP), and a decrease in cell number $(24,25)$. Possible direct as well as indirect effects of NFT on the protein synthetic ability of the pyramidal neurons in $\mathrm{AD}$ were determined by measuring (i) the GA size and cell profile area of AD patients and controls, (ii) the size of the GA and cell profile area of NFT-bearing or non-NFT-bearing neurons of AD patients, and (iii) the density of extraneuronal NFT around every neuron stained for the GA.

\section{MATERIALS AND METHODS}

\section{Tissue Preparation}

Brains of 14 human subjects were obtained at autopsy (see Table 1 for details and clinico-pathological information). The material consisted of six non-demented 58-85-year-old controls (74 \pm 4 years of age) without any primary neurological or psychiatric disorder and eight Alzheimer patients aged 54-88 years $(73 \pm 4$ years of age). There was no significant difference in age $(p=0.10)$ or brain weight $(p=0.08)$ between controls and AD patients. Although there was a significant difference in postmortem delay between controls and AD patients $(p=0.02)$, there was no significant relationship between the size of the GA and postmortem delay $(\mathrm{p}=0.07)$. Therefore, the difference in postmortem delays did not influence the results. The diagnosis "probable AD" was established by excluding other possible causes of dementia according to NINCDS-ADRDA criteria (26). All patients had a global deterioration scale of 5-7 for severity of dementia (27) (Table 1) and neuropathological examination showed extensive neocortical and hippocampal SP and NFT. Brains were removed at autopsy and weighed. The hippocampus containing the CA1 area was dissected and fixed at room temperature in $4 \%$ buffered formaldehyde for about 1 month. The fixed hippocampus was dehydrated in graded ethanol, embedded in paraffin and cut serially in $6 \mu \mathrm{m}$ thin frontal sections. The sections were mounted on chrome-aluminum-sulphate-coated slides, deparaffinized, hydrated and stained either by thionine $(0.5 \%)$, Bodian silver staining or immunocytochemistry for MG-160, a protein marker of the GA.

A polyclonal antibody has been raised against immunoaffinity purified MG-160, a sialoglycoprotein of medial cisternae of rat neuronal GA. This antibody recognizes the medial cisternae of the GA of neurons and glia in formalin-fixed, paraffin-embedded tissue of the human brain (28). The specificity of the antibody for GA membranes had been earlier established (29). By immunocytochemistry at the electron microscopic level, performed on human temporal lobe excised for epilepsy, the antibody stained exclusively the GA of neurons (28). For optimal retrieval of the MG-160 antigen, we used microwave oven treatment before incubating tissue sections with the first antibody (15). The immunocytochemical procedures have already been described extensively $(15,16)$. Briefly, the sections were incubated with anti-MG-160 diluted 1:800 for 1 hour at room temperature followed by an overnight incubation at $4^{\circ} \mathrm{C}$. Subsequently the sections were washed in Tris-buffered saline and incubated with biotinylated goat anti-rabbit (Vector Laboratories Inc.) at a dilution of 1:500 for 30 minutes and finally with 
avidin-biotin coupled to peroxidase (Vector Laboratories Inc.) at a dilution of 1:1,500 for 1 hour. 3',3'-Diaminobenzidine tetrahydrochloride (Sigma) was used as a chromogen. Staining enhancement was obtained by adding ammonium nickel sulphate $(2.2 \mathrm{mg} / \mathrm{ml})(30)$. Following the measurement of the size of the cell profile area and the GA in the sections stained with antiMG-160, the coverslip was removed and the sections stained for NFT and SP using a modified Bodian's method (31).

\section{Morphometry}

In order to avoid a possible effect of the silver staining on the measurement of the GA size, the staining and measurement of the GA size were performed prior to the silver staining. Briefly there were three steps in the measurement: 1) Measurement of the GA size and neuronal cell profile by an IBAS-KAT image analysis system (Kontron). Details of the morphometrical and sampling methods have been described earlier (16). Subsequently, in order to visualize the NFT, the coverslip was removed and the section stained with silver. Briefly, step one consists of seven stages: i) outlining of the CA1 area using a $2.5 \times$ objective, followed by ii) superimposing a grid (indicating the area seen at $40 \times$ ) over the CAl area, iii) random sampling of 30-40 fields by the computer, iv) calculating and saving of the scanning stage coordinates using a $2.5 \times$ objective, v) loading of the selected fields at a $40 \times$ objective, vi) making a mask for the stained GA in every cell (the size of the GA per cell consisted of the sum of all cytoplasmic areas stained with antiMG-160), followed by vii) manually outlining of the neurons and measuring the mask and cell profile area by using a $40 \times$ objective. Furthermore, at this stage the scanning coordinates of every outlined cell were stored together with the images. 2) Retrieval of every neuron measured in step one to observe whether it contained NFT. 3) Measurement of the density of extraneuronal NFT in a circle with the retrieved neuron in the center and a diameter of $247 \mu \mathrm{m}$ (the largest circular area on the screen) around every measured cell. All data were stored in Ascii format and used for statistical evaluation.

\section{Statistical Methods}

Using an SPSS program (SPSS Inc., Chicago), a multiple regression method was applied to study the relationship between the different variables. Furthermore, Student's $t$-test was used to compare variables between controls and AD subjects. A $p<0.05$ was considered to be significant.

\section{RESULTS}

Following the Bodian staining we were able to distinguish both intra- and extraneuronal NFT in sections which had previously been stained for the GA. In order to exclude a possible interference of the immunocytochemical staining of the GA on the subsequent silver staining, the NFT density was determined using an image analysis system in ten alternating sections (from two patients \#88252 and \#87017) that were either stained by silver only or by silver staining following the immunocytochemical staining for the GA. Using one way ANOVA, no significant effect of the immunocytochemical GA staining on the NFT density was observed $(p=0.71)$.
The GA staining appeared as cytoplasmic granular perinuclear structures (Fig. 1A). The GA size was generally smaller in AD patients than in non-demented controls. Bodian silver staining clearly showed the presence of NFT and SP in old controls and all AD patients (Table 1). Microscopically, a large proportion of the neurons in the CA1 area of the hippocampus contained NFT (Fig. 1B). Counting both intra- and extraneuronal NFT in controls and AD patients showed a clear difference $(\mathrm{p}=3.59$ $\times 10^{-5}$ ) in the number of NFT in the CA1 area (Table 1). Of the 860 NFT counted, $74.4 \%$ were intracellular and $25.6 \%$ extracellular.

The Student's $t$-test showed a significant decrease in the GA size of AD patients compared to controls ( $\mathrm{p}=$ $0.01)$. There was no difference in cell profile area between controls and AD patients $(p=0.85)$ (Table 2). Furthermore, the ratio of the GA size to the cell profile area was significantly smaller in AD patients (7.62\%) than controls $(12.42 \%)(\mathrm{p}=0.011)$. The size of the GA in NFT-bearing cells $(28 \pm 0.27)$ was generally larger than that of NFT-free neurons $(17.80 \pm 0.26)$. However, using multiple regression tests to study the possible correlation between different variables, no significant correlation was found between the presence of intracellular NFT $(p=0.44)$, the density of extraneuronal NFT around that cell $(p=0.18)$, and the size of the GA per cell (Table 3).

\section{DISCUSSION}

In previous studies of the $\mathrm{GA}$ in normal aging, $\mathrm{AD}$ and amyotrophic lateral sclerosis, we showed that the morphometric analysis on the immunocytochemically detected GA is a reliable index of neuronal activity in different regions, including the supraoptic nucleus $(14,15)$ and nucleus tuberalis lateralis (17) in the hypothalamus, nucleus basalis of Meynert (16) in basal forebrain and of motor neurons in the spinal cord $(32,33)$. In the present study, using the size of the GA as an index of metabolic activity, we showed that in $\mathrm{AD}$ the protein synthetic or secretory function of neurons was decreased in both tangle-bearing and non-tangle-bearing neurons in the CA1 area of the hippocampus. However, the presence or absence of intra- or extracellular NFT did not affect the extent to which the protein synthetic ability of the neurons in this area was reduced.

The present study shows also that although the pyramidal neurons of the CA1 area in AD contain a smaller GA, this change is not reflected in a significant decrease in the cell profile area. This indicates that the size of the GA is a more sensitive parameter for neuronal activity than cell size, an observation which agrees with previous reports $(14,16)$. Furthermore, a multiple regression analysis of the relationship between the size of the GA and the cell profile area, the presence or absence of intracellular NFT and the density of extraneuronal NFT showed 


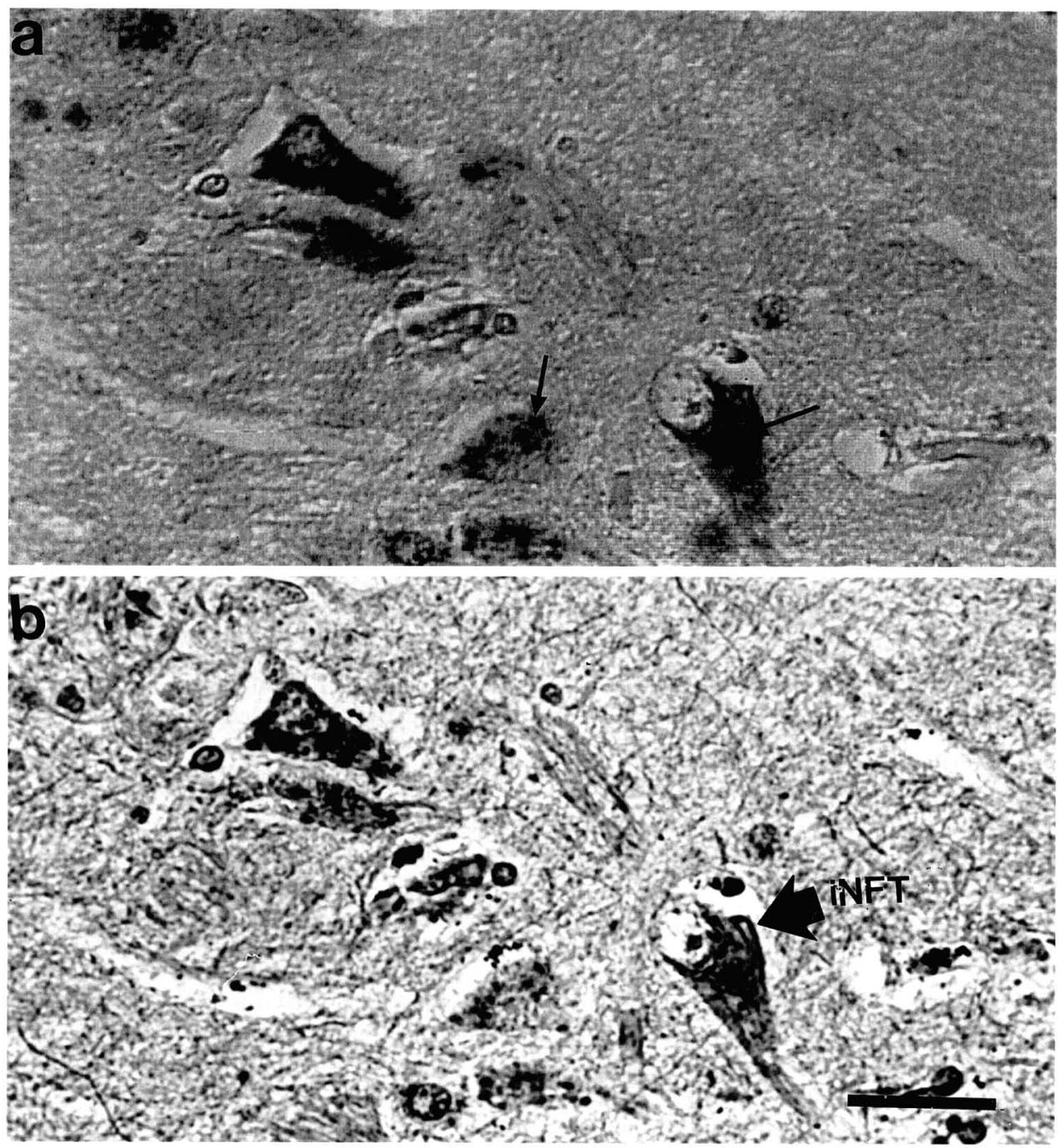

Fig. 1. Immunocytochemical staining of the GA (arrows) in an Alzheimer patient (a). Silver staining of the same group of neurons in the same section (b). iNFT $=$ intraneuronal neurofibrillary tangle. Bar $=30 \mu \mathrm{m}$.

that the reduced size of the neuronal GA did not correlate with the presence or absence of NFT (Table 3 ).

The smaller GA in AD is an index of reduced protein synthetic capability, which agrees with the observation that in $\mathrm{AD}$ the brain contains less protein (8), smaller nucleoli and less mRNA (12). Furthermore, it is in accordance with the data of Mann (12) which showed a significant decrease in RNA content, nuclear and nucle-

TABLE 2

The Size of the GA and Cell Profile in the CA1 Area of the Hippocampus

\begin{tabular}{lrrc}
\hline & Control & Alzheimer & $\mathrm{p}^{*}$ \\
\hline Golgi apparatus $/ \mu \mathrm{m}^{2}$ & $31.3 \pm 3.7$ & $19.3 \pm 2.7$ & 0.015 \\
Cell profile area/ $\mu \mathrm{m}^{2}$ & $252.7 \pm 20$ & $247.5 \pm 17$ & 0.850 \\
Ratio (Golgi/cell) \% & $12.4 \pm 0.1$ & $7.7 \pm 0.1$ & 0.011 \\
\hline
\end{tabular}

* Student's $t$-test. olar volume in both tangle-bearing and non-tangle-bearing cortical neurons in AD.

A number of studies have focused on the possible relationship between the presence of NFT in the neurons

TABLE 3

Analysis of the Relationship between the Size of the GA and Cell Profile Area, the Presence or Absence of NFT and the Density of Extraneuronal NFT in a Circle with a Diameter of $247 \mu \mathrm{m}$ around each Neuron in AD Patients

\begin{tabular}{ll}
\hline \multicolumn{1}{c}{ Variable } & Sig. T* \\
\hline Cell profile area & 0.0000 \\
Ratio (GA size/cell profile area) & 0.0000 \\
NFT (presence or absence) & 0.4454 \\
Density of extraneuronal NFT & 0.1765 \\
\hline
\end{tabular}

* Multiple regression (participation in total significance of correlation which is $<0.0000)$. 
of AD patients and the reduction of protein synthetic capability $(11,19,34-36)$. Using the size of the nucleolus as an indicator of neuronal metabolic activity, Dayan and Ball (19) reported a clear decrease in the size of the nucleolus in NFT-bearing neurons compared to the adjacent non-NFT-bearing neurons in the temporal cortex. However, Curcio and Kemper (34) did not find such a reduction in nucleolar size in the nucleus raphe dorsalis, where tangle formation is prominent. It has been suggested that one reason for this controversy is the difficulty of accurately measuring the size of the nucleolus (37). An alternative explanation is that the presence of NFT and the reduced metabolism in $\mathrm{AD}$ are basically two independent phenomena that may in some areas sometimes be present in the same neurons. The last possibility is in accordance with our present data which show that the decreased size of the GA, which is clearly present in $\mathrm{AD}$, is not related to the presence of intra- or extraneuronal NFT. Furthermore, the possibility that these two phenomena are independent is in accordance with the observation of Gertz et al (35), who showed that the presence of intraneuronal NFT in the CA1 area of the hippocampus is not related to nucleolar or cell size. Taken together, all these data suggest that a reduced protein synthetic ability of neurons is present in $\mathrm{AD}$ that does not, however, directly correlate with the formation of NFT.

We have shown earlier that the protein synthetic and secretory ability as determined by the size of the GA remains unchanged in neurons showing only pretangle stages of cytoskeletal alterations (17). This conclusion is based on measurements in the nucleus tuberalis lateralis, an area of the human hypothalamus in which silverstained NFT are not present, although intense staining with $\mathrm{Alz}-50(23,38)$ and other antibodies against cytoskeletal alterations in $\mathrm{AD}$, i.e. tau-1 and 3-39 (anti-ubiquitin) (23), are prominently staining cell bodies and dystrophic neurites.

The present paper indicates that the formation of NFT, a major hallmark of $\mathrm{AD}$, and decreased neuronal protein synthetic ability are not directly related. However, since every staining method for NFT has its limitations (21), confirmation of these results with other methods of NFT staining in other brain areas would be important. In addition, we are developing a method to study the relationship between the presence of SP and the GA size in AD.

It has been shown in tissues obtained at autopsy that in $\mathrm{AD}$ the major constituent of PHF, i.e. tau, is abnormally phosphorylated (1-3), although this has also been observed in biopsies from control brains (39). Key enzymes for the phosphorylation of tau in PHF are a group of protein kinases, e.g. tau protein kinase-1 and PK40 erk. Recently, Blanchard and colleagues (40) have shown that one of the major factors in the determination of PK40 erk activity is the level of ATP. Furthermore, it has been shown recently that in $\mathrm{AD}$ the level of cytochrome oxi- dase which is involved in ATP production (41) is reduced in both areas which are affected heavily by NFT (e.g. CA1) and in the areas which are relatively spared from these changes (e.g. the molecular layer of the dentate gyrus) $(42,43)$. It remains to be studied, however, whether within an area like CA1 the reduction of cytochrome oxidase is different between NFT-bearing and NFT-free neurons.

\section{ACKNOWLEDGMENTS}

We are grateful to Dr. C. W. Pool for his essential work on the development of the software used in this study. We wish to thank Prof. Dr. F. C. Stam (Netherlands Brain Bank, Amsterdam), Dr. W. Kamphorst (Free University, Amsterdam) and Dr. D. Troost (Academic Medical Center, Amsterdam) for their neuropathological diagnoses. Much appreciation is expressed to Ms. O. Pach for her expert secretarial assistance. Human brain tissue was obtained from the Netherlands Brain Bank, Amsterdam (coordinator Dr. R. Ravid).

\section{REFERENCES}

1. Grundke-Iqbal I, Iqbal K, Quinlan M, Tung Y-C, Zaidi MS, Wisniewski HM. Microtubule-associated protein tau, a component of paired helical filaments. J Biol Chem 1986a;261:6084-9

2. Grundke-Iqbal I, Iqbal K, Tung Y-C, Quinlan M, Wisniewski HM, Binder LI. Abnormal phosphorylation of the microtubule associated protein tau in Alzheimer cytoskeletal pathology. Proc Natl Acad Sci USA $1986 b ; 83: 4913-17$

3. Iqbal K, Grundke-Iqbal I, Smith AJ, George L, Tung Y-C, Zaidi T. Identification and localization of a tau peptide at paired helical filaments of Alzheimer disease. Proc Natl Acad Sci USA 1989;86: $5646-50$

4. Arriagada PV, Growdon JH, Hedley-Whyte ET, Hyman BT. Neurofibrillary tangles but not senile plaques parallel duration and severity of Alzheimer's disease. Neurology 1992;42:631-9

5. Anderson FH, Richardson EP, Okazaki H, Brody JA. Neurofibrillary degeneration on Guam: Frequency in Chamorros and non-Chamorros with no known neurological disease. Biochemistry $1979 ; 102: 65-78$

6. Corsellis JAN. The aftermath of boxing. Psychol Med 1973;3: $270-3$

7. Swaab DF. Brain aging and Alzheimer's disease: "Wear and tear" versus "use it or lose it". Neurobiol Aging 1991;12:317-24

8. Suzuki K, Katzman R, Korey SR. Chemical studies on Alzheimer's disease. J Neuropathol Exp Neurol 1965;24:211-24

9. Sajdel-Sulkowska EM, Coughlin JF, Staton DM, Moratta CA. In vitro protein synthesis by messenger RNA from the Alzheimer's disease brain. In: Katzman R, ed. Banbury Report 15: Biological Aspects of Alzheimer's Disease. Cold Spring: Cold Spring Harbor Lab, 1983:193-300

10. Bowen DM, Smith CB, White P, Flack PH, Carrasco LH, Gedye JL, Davison AN. Chemical pathology of the organic dementias. Brain 1977; 100:427-53

11. Doebler JA, Markesbery WR, Anthony A, Rhoads RE. Neuronal RNA in relation to neuronal loss and neurofibrillary pathology in the hippocampus in Alzheimer's disease. J Neuropathol Exp Neurol 1987;46:28-39

12. Mann DMA, Neary D, Yates PO, Lincoln J, Snowden JS, Stanworth P. Alterations in protein synthetic capability of nerve cells in Alzheimer's disease. J Neurol Neurosurg Psychiatry 1981;44:97102

13. Hoyer S, Oesterreich K, Wagner O. Glucose metabolism as the site of the primary abnormality in early-onset dementia of Alzheimer type? J Neurol 1988;235:143-8 
14. Lucassen PJ, Salehi A, Pool CW, Gonatas NK, Swaab DF. Activation of vasopressin neurons in aging and Alzheimer's disease. J Endocrinol 1994;6:673-9

15. Lucassen PJ, Ravid R, Gonatas NK, Swaab DF. Activation of the human supraoptic and paraventricular nucleus neurons with aging and in Alzheimer's disease as judged from increasing size of the Golgi apparatus. Brain Res 1993;632:105-13

16. Salehi A, Lucassen PJ, Pool CW, Ravid R, Gonatas NK, Swaab DF. Decreased neuronal activity in the nucleus basalis of Meynert in Alzheimer's disease as suggested by the size of the Golgi apparatus. Neuroscience 1994;4:871-80

17. Salehi A, Van de Nes JAP, Hofman MA, Gonatas NK, Swaab DF. Early cytoskeletal changes as shown by Alz-50 are not accompanied by decreased neuronal activity. Brain Res 1995;678:29-39

18. Swaab DF, Jongkind JF, De Ryke-Arkenbout AA. Quantitative histochemical study on the influence of lactation and changing levels of gonadotropic hormones on rat supraoptic nucleus. Endocrinology 1971;89:1123-5

19. Dayan AD, Ball MJ. Histometric observations on the metabolism of tangle-bearing neurons. J Neurol Sci 1973;19:433-6

20. Saper CB, German DC. Hypothalamic pathology in Alzheimer's disease. Neurosci Lett 1987;74:364-70

21. Duyckaerts C, Delaère P, Hauw J-J, et al. Rating of the lesions in senile dementia of the Alzheimer type: Concordance between laboratories. A European multicenter study under the auspices of EURAGE. J Neurol Sci 1990;97:295-323

22. Byne W, Mattiace L, Kress Y, Davies P. Alz-50 immunoreactivity in the hypothalamus of the normal and Alzheimer human and the rat. J Comp Neurol 1991;306:602-12

23. Swaab DF, Grundke-Iqbal I, Iqbal K, Kremer HPH, Ravid R, Van de Nes JAP. Tau and ubiquitin in human hypothalamus in aging and Alzheimer's disease. Brain Res 1992;590:239-49

24. Van Hoesen GW, Hyman BT. Hippocampal formation: Anatomy and the patterns of pathology in Alzheimer's disease. In: StormMathisen J, Zimmer J, Ottersen OP, eds. Understanding the brain through hippocampus. The hippocampal region as a model for studying brain structure and function. Progress in Brain Research. Vol 83. Amsterdam: Elsevier Science Publishers B.V, 1990:445-57

25. West MJ, Coleman PD, Flood DG, Troncoso JC. Differences in the pattern of hippocampal neuronal loss in normal ageing and Alzheimer's disease. Lancet 1994;344:769-72

26. McKhann G, Drachman D, Folstein M, Katzman R, Price D, Stadlan EM. Clinical diagnosis of Alzheimer's disease: Report of NINCDS-ADRDA Work Group under the Auspices of Department of Health and Human Services Task Force on Alzheimer's Disease. Neurology 1984;34:939-44

27. Reisberg B, Ferris SH, De Leon MJ, Crook T. The Global Deterioration Scale for assessment of primary degenerative dementia. Am J Psychiatry 1982;139:1136-9

28. Croul S, Mezitis SGE, Stieber A, Chen Y, Gonatas JO, Goud B, Gonatas NK. Immunocytochemical visualization of the Golgi apparatus in several species, including human, and tissues with an antiserum against MG-160, a sialoglycoprotein of rat Golgi apparatus. J Histochem Cytochem 1990;38:957-63

29. Gonatas JO, Mezitis SGE, Stieber A, Fleischer B, Gonatas NK. MG-160, a novel sialoglycoprotein of the medial cisternae of the Golgi apparatus. J Biol Chem 1989;264:646-53

30. Adams JC. Heavy metal intensification of DAB-based HRP reaction product. J Histochem Cytochem 1981;29:775

31. Bodian D. A new method for staining nerve fibers and nerve endings in mounted paraffin sections. Anat Rec 1936;65:89-97

32. Mourelatos Z, Yachnis A, Rorke L, Mikol J, Gonatas NK. The Golgi apparatus of motor neurons in amyotrophic lateral sclerosis Ann Neurol 1993;33:608-15

33. Gonatas NK, Steiber A, Mourelatos Z, et al. Fragmentation of the Golgi apparatus of motor neurons in amyotrophic lateral sclerosis. Am J Pathol 1992;140:731-7

34. Curcio CA, Kemper T. Nucleus raphe dorsalis in dementia of the Alzheimer type: Neurofibrillary changes and neuronal packing density. J Neuropathol Exp Neurol 1984;43:359-68

35. Gertz HJ, Schoknecht G, Krüger H, Cervos-Navarro J. Stability of cell size and nucleolar size in tangle-bearing neurons of hippocampus in Alzheimer's disease. Brain Res 1989;487:373-5

36. Mann DMA, Neary D, Yates PO, Lincoln J, Snowden JS, Stanworth P. Neurofibrillary pathology and protein synthetic capability in nerve cells in Alzheimer's disease. Neuropathol Appl Neurobiol $1981 ; 7: 37-47$

37. Tomlinson BE. Aging and the dementias. In: Adams JH, Duchen LW, eds. Greenfield's Neuropathology. London: Edward Arnold, 1992:1284-1410

38. Van de Nes JAP, Kamphorst W, Ravid R, Swaab DF. The distribution of Alz-50 immunoreactivity in the hypothalamus and adjoining areas of Alzheimer's disease patients. Brain 1993;116: 103-15

39. Matsuo ES, Shin R-W, Billingsley ML, Voorde A, O'Connor M, Trojanowski JQ, Lee VM-Y. Biopsy-derived adult human brain tau is phosphorylated at many of the same sites as Alzheimer's disease paired helical filaments tau. Neuron 1994;13:989-1002

40. Blanchard BJ, Raghunandan RD, Roder HM, Ingram VM. Hyperphosphorylation of human tau by brain kinase PK40 crk beyond phosphorylation by cAMP-dependent PKA: Relation to Alzheimer's disease. Biochem Biophys Res Commun 1994;200:187-94

41. Chandrasekaran K, Giordano T, Brady DR, Stoll J, Martin LJ, Rapoport SI. Impairment in mitochondrial cytochrome oxidase gene expression in Alzheimer's disease. Mol Brain Res 1994;24:336-40

42. Simonian NA, Hyman BT. Functional alterations in Alzheimer's disease: Diminution of cytochrome oxidase in the hippocampal formation. J Neuropathol Exp Neurol 1993;6:580-5

43. Simonian NA, Hyman BT. Functional alterations in Alzheimer's disease: Selective loss of mitochondrial-encoded cytochrome oxidase mRNA in the hippocampal formation. J Neuropathol Exp Neurol 1994;5:508-12

Received March 6, 1995

Revision received May 24, 1995

Accepted May 24, 1995 